\title{
In vivo Real-time Monitoring of Aphrodisiac Pheromone Release of Small White Cabbage Butterflies (Pieris rapae)
}

\author{
Yue $\mathrm{Li}^{\dagger}$ and Robert A. Mathews* \\ ${ }^{\dagger}$ Department of Chemistry and Biochemistry, University of Maryland, College Park, MD 20742 \\ *Department of Entomology, Smithsonian Institution, National Museum of Natural History, \\ Washington, D.C. 20013
}

\section{Abstract}

The study of insect behavior is of practical importance for developing possible control methods in Integrated Pest Management. Currently, one model of butterfly mating behavior suggests that the initial location of potential mates occurs visually followed by the release of one or more short-range male aphrodisiac pheromones. This model is supported by data obtained from field observations and inferences based on the behavioral effects of chemicals extracted or isolated using indirect and offline techniques. In this study, we performed in vivo real-time monitoring of the male aphrodisiac pheromones released by the small white cabbage male butterfly (Pieris rapae Linnaeus) using confined direct analysis in real time (cDART) mass spectrometry. cDART is a new method easily adapted to the study in real time of chemicals released into the environment by virtually any insect. The major compound released by the male Pieris rapae was identified as ferrulactone. The experimental results reported here indicate that the release of ferrulactone occurs less than 1 second after the male visualizes its partner, and reaches a maximum after about one half minute. This study is the first reported in vivo detection and monitoring of butterfly male aphrodisiac pheromones in real time.

Key Words - Pieris rapae, aphrodisiac pheromone, ferrulactone, real-time analysis, DART, mass spectrometry

*Address reprint requests to Dr. Robert A. Mathews, Department of Entomology, Smithsonian Institution, National Museum of Natural History, Washington, D.C. 20013, USA. Email: mathewsr@ si.edu or ${ }^{\dagger}$ Yue Li, Department of Chemistry and Biochemistry, University of Maryland, College Park, MD 20742, USA. Email: yueli@umd.edu 


\section{INTRODUCTION}

Insects are well known to produce a diverse variety of sex pheromones to attract the opposite sex of the same species and to induce mating behavior (Karlson and Betenandt, 1959; Nieberding et al., 2008; Tillman et al., 1999; Witzgall et al., 2010). Characterization of these semiochemicals is important not only for understanding the biology and biochemistry of insects, but also for the environmental and agricultural sciences. Due to their diurnal lifestyle, butterflies have been considered as a microsmatic group of insects (Carlsson et al., 2013) that rely on visualization for communication and defense (Costanzo and Monteiro, 2007; Obara et al., 2008; Rutowski, 1991). Visual signals include color (Robertson and Monteiro, 2005) and ultraviolet reflectance (Obara and Hidaka, 1968; Papke et al., 2007), which may be complemented by chemical signals (Costanzo and Monteiro, 2007).

About 70 years ago, Tinbergen studied the courtship behavior of Eumenis semele Satyridae (Tinbergen et al., 1942). He suggested that mating was enhanced by the presence of some scent substances from the male butterflies. This insight was expanded by Brower and co-workers, who demonstrated that male Danaus gilippus use pheromones during courtship behavior to facilitate mating (Meinwald et al., 1966). Rutowski's studies have also shown that epicuticular components of male Eurema lisa and Colias philodice elicit acceptance behavior by females (Rutowski, 1977a; Rutowski, 1977b; Rutowski, 1980). Subsequently, the utilization of pheromones by butterflies has been studied quite extensively (Hayashi et al., 1987; Kan and Hidaka, 1997; Karlson and Schneide.D, 1973; Nishida et al., 1996; Schulz and Nishida, 1996). The male aphrodisiac pheromones have been reported to be mainly released from secretory cells on the forewing in some species (Hedenstrom et al., 2015; Nieberding et al., 2008; Omura et al., 2001).

The small white cabbage butterfly (Pieris rapae Linnaeus) is common in many parts around the world. Despite wide geographic distribution and agricultural importance, their intraspecific chemical communication system has not been fully described. Recently, Yildizhan et al. (Yildizhan et al., 2009) have comprehensively studied the small white cabbage butterfly and the large white cabbage butterfly, Pieris brassicae Linnaeus. They found that the males of the two 
species possess two macrolide lactones on their forewings: ferrulactone $\left(\mathrm{C}_{12} \mathrm{H}_{18} \mathrm{O}_{2}\right)$ and 64 brassicalactone $\left(\mathrm{C}_{17} \mathrm{H}_{26} \mathrm{O}_{2}\right)$, respectively. They further demonstrated that the two lactones enhanced mating success, suggesting that they are pheromones with aphrodisiac properties. In 2007, Andersson et al. (Andersson et al., 2007) reported that a similar species, Pieris napi

67 Linnaeus, releases some male specific pheromones comprised of geranial $\left(\mathrm{C}_{10} \mathrm{H}_{16} \mathrm{O}\right)$ and neral $\left(\mathrm{C}_{10} \mathrm{H}_{16} \mathrm{O}\right)$ in a 1:1 ratio. They suggested that the release of the above mixture is merely a passive physical process during flight.

So far, almost all chemicals released by insects for defensive, reproductive, and other purposes have been detected and identified using indirect and offline techniques, such as liquid extraction of whole body, wing, or organs (Lessman et al., 1989; Nishida et al., 1996; Schulz et al., 1993; Schulz and Nishida, 1996) or by ambient adsorption followed by instrumental analysis, usually with GC-MS. The advantage of these conventional approaches is that the volatile compounds can be concentrated in solvents or on the surface of the absorbing materials, leading to increased detection sensitivity. However, the methods need a certain period of time for sample collection, preparation and measurements (minutes to hours), thus they preclude any possibility of real-time analysis. The insect behavior and release of aphrodisiac pheromones are highly dynamic, and can quickly change with time and external environment. As the result, valuable information can be lost during the above sampling and analysis procedures.

The detection and characterization of semiochemicals that insects emit in real time should contribute significant new insights into their behavior. So far, very few studies have been reported in the literature that described the detection of volatile semiochemicals coincident with insect behavior in real time until the recent advancements of new mass spectrometry techniques. These new techniques allow one perform sampling under ambient conditions and observations in real time. The studies include the analysis of cuticular hydrocarbons of Drosophila (Yew et al., 2008), and female-female wasp behavioral contests (Goubault et al., 2006).

As a new atmospheric pressure ion source, DART has been successfully used in analyses of solid, 92 liquid, and gaseous samples under ambient conditions without need of sample preparation 93 (Chernetsova et al., 2011; Cody, 2009). Recent applications of DART include the analyses of 
organometallic compounds (Borges et al., 2009), medicinal plants (Kim et al., 2010), flavor and fragrances (Haefliger and Jeckelmann, 2007) and identification of volatiles from eucalyptus (Maleknia et al., 2009). A possible problem with gaseous sample analysis is the low sensitivity of the DART source due to open-air sampling. Recently, one of the authors developed the confined DART ion source (cDART), in which the plasma generated by the atmospheric pressure glow discharge ionizes gas-phase molecules in a T-shaped flow tube instead of open air (Li, 2012). The cDART design leads to an increase of ionization efficiency of gaseous samples by two or three orders of magnitude. The cDART source has been applied in real time analysis of plant wound response $(\mathrm{Li}, 2012)$ and online in vivo analysis of human breath $(\mathrm{Li}, 2013)$.

In this article, we report the experimental results of real-time monitoring of the aphrodisiac pheromones released by male small white cabbage butterflies ( $P$. rapae). To the best of our knowledge, this report is the first in vivo real time detection and identification of pheromones released by butterflies coincident with their normal behavior.

\section{EXPERIMENTAL SECTION}

Instruments: The experiments were performed with a Time-of-Flight mass spectrometer (AccuTOF JEOL USA Inc.), equipped with a DART ion source. The instrument was operated in the positive or negative ion mode with a resolving power of 6000 (FWHM). Mass spectra were acquired at a rate of one spectrum per second. Calibration for exact mass measurements was accomplished using polyethylene glycol (average molar mass 600) as the internal standard. Typical mass accuracy obtained in this study was less than $5 \mathrm{ppm}$. The exact mass measurements and isotopic distribution comparisons were used to determine the molecular formulas of the ions observed in mass spectra. In the experiments, the gas heater was set to 250 ${ }^{\circ} \mathrm{C}$, the helium flow rate was $1 \mathrm{~L} / \mathrm{min}$, and the glow discharge needle potential and the grid voltage were set at $3.5 \mathrm{kV}$ and $250 \mathrm{~V}$, respectively. The AccuTOF MS settings are as follows: orifice 1 temperature $=80^{\circ} \mathrm{C}$, orifice $1=20 \mathrm{~V}$, orifice $2=5 \mathrm{~V}$, ring $=5 \mathrm{~V}$. In the in-source collision-induced dissociation (CID) measurements, the orifice 1 voltage was increased to $65 \mathrm{~V}$ and $90 \mathrm{~V}$, respectively. 
Specimens: Most specimens of $P$. rapae were captured in the Silver Spring area of Maryland and identified by Dr. Brian Harris, Department of Entomology, National Museum of Natural History, Smithsonian Institution, Washington, D.C.. Some specimens were raised privately and some were provided by Professor Nathan I. Morehouse of the University of Pittsburg.

cDART Measurements: The experiments in this study were performed under the general room lighting (fluorescent light). The setup of the confined DART source is similar with the one used in the study of plant wound response (Li, 2012), as shown in Fig. 1. In brief, specimens of $P$. rapae were placed individually or together in a clear I-Chem jar $(150 \mathrm{~mL}, 6 \mathrm{~cm}$ wide by $7 \mathrm{~cm}$ high, VWR LLC, PA) equipped with a lid containing a septum. Air was used as the carrier gas instead of nitrogen to prevent suffocation. In the experiments, a line of PEEK tubing (1/16"' OD, 0.010" ID) from a compressed air cylinder was inserted into the septum and placed near the bottom of the jar. The second PEEK tubing (15 cm in length) was used to connect to the second jar or to the cDART ion source. The flow rate of air was controlled by a flow meter. Based on this setup, the gas molecules in the jars follow the air flow and enter the DART interface, where they collide and react with high energy metastable molecules produced by the atmospheric pressure glow discharge. The volatile compounds released by butterflies can be continuously monitored using mass spectrometry. Compared to the open-air DART source, the confined interface efficiently reduces random diffusion of the gaseous analytes in the air and can significantly increase collision reaction probability resulting in higher ionization efficiency. For the experimental setup used in this study, the strongest signal was obtained at the air flow rate of about $0.2 \mathrm{~L} / \mathrm{min}$. This flow rate was thus used in all the experiments of this study.

SPME-GC-EI Measurements: As the AccuTOF mass spectrometer used in this study does not have MS/MS capability, to identify the dominant ions observed in the mass spectra, the compounds released by the butterflies were also analyzed using a conventional offline GC-MS method. Briefly, one male and one female butterfly were placed in a $150 \mathrm{~mL}$ jar with gentle agitation (to keep them flying). A Supelco manual SPME holder and a carboxen-PDMS coated fiber were used in the SPME experiments. The SPME fiber was introduced into the jar through a silicone septum, and was exposed for $1 \mathrm{hr}$ at room temperature. The SPME fiber was desorbed in the hot $\mathrm{GC}$ injector port $\left(250{ }^{\circ} \mathrm{C}\right.$, splitless $)$ for 2 mins prior to analysis. 
157 The gas chromatography measurements were performed on an Agilent 6890N system coupled with a JEOL high resolution magnetic sector mass spectrometer (JMS-700 MStation) with the EI ion source $(70 \mathrm{eV})$. The mass spectrometer was operated in the mode of high scan speed and low resolution (1000) with the mass range from 40 to 500 daltons. The silica capillary column (Agilent HP-5MS, 30 m length, $250 \mu \mathrm{m}$ I.D.) was used in the experiments with helium (at 1 $\mathrm{mL} / \mathrm{min}$ ) as the carrier gas. Analysis was performed as follows: the column temperature was programmed from $30^{\circ} \mathrm{C}$ at $1.5 \mathrm{mins}$, increased to $250{ }^{\circ} \mathrm{C}$ at the rate of $14^{\circ} \mathrm{C} / \mathrm{min}$ and held at 250 ${ }^{\circ} \mathrm{C}$ for another three minutes. The fragmentation patterns obtained by EI were used to identify

Chemicals: Polyethylene glycol was purchased from Sigma-Aldrich. Helium (99.999\%), compressed air, and nitrogen were purchased from Airgas.

\section{RESULTS AND DISCUSSION}

In this study, one or two specimens of $P$. rapae were placed in $150 \mathrm{~mL}$ jars equipped with septa, which were large enough to permit limited flying. The presence of volatile chemicals was continuously monitored in the mass range from 50 to 400 daltons using the experimental setup shown in Fig. 1, using single vessels or multiple vessels linked with tubing. Experiments were performed and repeated for at least 10 times in about three months and each specimen was only used for once. The experimental observations were consistent with one other (the coefficient of variation of the maximum ion counts was less than 20\%). The typical mass spectra obtained in the positive ion mode are shown in Fig. 2a, in which the top spectrum was obtained using two specimens (one male and one female) placed in a single jar, while the bottom was obtained using only one male. The figure shows that the signal from the latter is lower than obtained using two specimens by two orders of magnitude. The ion at $\mathrm{m} / \mathrm{z} 195.13$ is the dominant peak in both of mass spectra. Other weak ion peaks were observed including $m / z 81.05,102.08,135.14,159.14$, 184 177.13, 212.18 and 389.27. A similar analysis was performed in the negative ion mode, but only 185 a marginally weak signal was observed. Thus, only the results obtained in the positive ion mode 186 are discussed in this study. 
188 A similar setup has been successfully used in the study of online in vivo analysis of human 189 breath $(\mathrm{Li}, 2013)$. The calibration curves of four standard compounds including ethanol 190 (46.07 g/mol), acetone (58.08 g/mol), 2-hexanone (100.16 g/mol) and limonene $(136.24 \mathrm{~g} / \mathrm{mol})$ 191 were determined, and excellent linearity with coefficients of determination $\left(\mathrm{R}^{2}>0.99\right)$ was 192 obtained. The limit of detection (LOD) for analytes in the effluent was determined to be in the 193 low parts per billion ( $\mathrm{ppb})$ range.

Fig. $2 b$ shows the result of three-minute continuous monitoring of aphrodisiac pheromones released by one male in the presence of one female butterfly. The experimental observations show that the pheromone release was related to the flight activity of the butterflies. After the butterflies stopped flying at about 3.4 min, the signal decreased quickly.

With the objective of identifying the source of the pheromones (from male or female), we performed the following experiments. Two jars were linked with tubing with the incoming flow of air into the first jar and the effluent from the second jar was monitored in real time with cDART-MS. As shown in Fig. 2c, 0 to $2.7 \mathrm{~min}$, an empty jar was used to measure the background signal. At $2.8 \mathrm{~min}$, the jar was opened and a female butterfly was placed in the jar. From 5 to $7.2 \mathrm{~min}$, the second jar with another female butterfly was connected to the first jar. At this time, a visual barrier was used to keep the two butterflies invisible to each other, but shared the same air flow in the series, shown in the figure as F-F. At $7.2 \mathrm{~min}$, the lid of the second jar was opened and the second female butterfly was transferred into the first jar (indicated as FF in Fig. 2c) and the effluent air flow was monitored. No signal of any kind was detected in this 210 series of experiments except a weak intensity at $\mathrm{m} / \mathrm{z}$ 55.04, $\left(\mathrm{H}_{2} \mathrm{O}\right)_{3} \mathrm{H}^{+}$(Chernetsova et al., 2011; 211 Cody et al., 2005). In Fig. 2b, c and d, the relative intensities correspond to the total ion currents, 212 and the maximum ion counts are set as 100. In the figures, M-M corresponds to males in 213 separate jars; MM corresponds to males in the same jars; similar designations are made for other 214 combinations.

216 A similar experiment was performed for two male butterflies, starting at 8.8 min. At 13.8 min, 217 the second male was transferred into the first jar containing a male. Almost immediately, a 
strong ion signal was observed in the mass spectrum, indicating the release of almost a single compound of $\mathrm{m} / \mathrm{z} 195.13$ as shown in Fig. 2a. The signal reached the ion count maximum at about $1 / 2$ minute, and then gradually decreased. Typically, the ion intensity decreased to $50 \%$ of its maximum in about one minute. The specimen jar was re-opened to check background and prepared for next run analysis at $16 \mathrm{~min}$, resulting in the ion signal decreasing to zero.

A female and a male were monitored in a similar way, as shown as F (17.0 min) alone in the first jar and then adding a male to the second jar, F-M (18.0 min). The female was then moved from jar-1 to jar-2 with the male, FM (19.0 min). Fig. 2c shows that a signal comparable in intensity was observed for the female-male (FM) combination to the male-male (MM) combination. The male and female butterflies were then separately transferred to two different jars after the above experiment and the effluent air flow from each jar was monitored. The signals detected at these time points in Fig. 2c clearly indicate that the signal of $m / z 195.13$ was observed only when male $P$. rapae were present, indicating that the pheromone was released only from the male butterfly. A small signal observed from the female was most likely due to carry-over when the male and female butterflies shared the same jar. The absence of the above signal, when the butterflies were in separate but linked jars, indicates the absence of any detectable chemical signal that would serve a trigger for the male pheromone. It seems apparent that a visual signal of some kind is needed because only a very weak signal is observed when single males fly, as shown in Fig. 2a (bottom). The above results strongly suggest that single $P$. rapae females release no detectable compound into the ambient air flow, while paired with males.

Similar measurements were performed with different male-female combinations, and are shown in Fig. 2d, in which 0 to 1.2 min corresponds to the background signal. Time periods starting at 1.2 and 2.7 min correspond to the signals from a single male (M) and a male and female in two separate jars linked with tubing (M-F). Once again a strong ion signal was obtained at $4.3 \mathrm{~min}$, when the female was transferred to the jar containing the male $P$. rapae. The female was then removed and the signal was no longer observed (7.8-8.5 min). At $8.6 \mathrm{~min}$, a dead female butterfly of the same species was placed in the jar containing the male. The female has been dead for about 2 hours, and was kept in a box with ice packs before experiments. At 11.0 min, a different species of live butterfly (Eastern Tailed Blue, Cupido comyntas) was transferred to the 
249 jar with the same male. For the latter two periods, only a marginal ion signal was observed, as 250 shown as $\mathrm{MF}(\mathrm{d})$ and $\mathrm{MO}$ in the figure.

252 To identify the compounds observed in Fig. 2a, two additional independent experiments were 253 performed. In the first, the orifice 1 voltage of the AccuTOF mass spectrometer was increased to $25465 \mathrm{~V}$ and $90 \mathrm{~V}$ from $20 \mathrm{~V}$, respectively. The increased orifice voltage results in increased 255 collision energy of ions in the atmospheric pressure interface of the mass spectrometer, which 256 causes limited fragmentation of the ions present. The in-source CID results at two different 257 energies are very similar, thus only the mass spectrum obtained at $65 \mathrm{~V}$ is shown in Fig. 3a. The 258 mass spectra in Fig. 2a are dominated by the ion at $m / z$ 195.13. Thus, the ion peaks observed in 259 the in-source CID spectra should correspond to the fragments from the ion. A series of the 260 fragments are observed with the major ions at $m / z$ 81.03, 95.05, 135.11, 159.13, and 177.13. The 261 ion at $\mathrm{m} / \mathrm{z} 177$ corresponds to the product of losing the $-\mathrm{OH}$ group after ring opening. The 159 262 and 149 ions should be the products of losing the other -OH group and - $\mathrm{CO}$ group from the 177 263 ion, respectively. Comparing the CID spectra to Fig. 2a indicates that most of the weak peaks 264 observed in Fig. 2a should correspond to the fragments of the $m / z 195.13$ ion. Therefore, the 265 ions derived from $\mathrm{m} / \mathrm{z}, 195$ are the primary signals observed in the pheromone-monitoring 266 experiments.

The AccuTOF mass spectrometer used in this study does not have MS/MS capability. Thus, the 269 SPME-GC-EI approach was also used, as discussed in the experimental section, to identify the dominant ion observed in the cDART mass spectra. The $m / z, 195$ ion should correspond to a 271 protonated product in the positive mode. The compound was observed at $\mathrm{m} / \mathrm{z} 194$ in the EI mass 272 spectrum. The fragmentation pattern of the ion is shown in Fig. 3b. The dominant fragments 273 correspond to $m / z 41,53,68,81,99,127$ and 179. The above GC-EI result is consistent with the 274 result reported by Yildizhan et al. (Yildizhan et al., 2009). Thus, we identified the $m / z 195.13$ 275 ion observed in the cDART measurements as protonated ferrulactone $\left(\mathrm{C}_{12} \mathrm{H}_{18} \mathrm{O}_{2}\right.$, molar mass 276 194). The peaks at $m / z 212.17$ and 389.27 should correspond to the ammonium adduct and 277 dimerized ions of ferrulactone, respectively. 
Our experimental results clearly show the following: (1) Only male $P$. rapae releases an almost 280 single chemical of molecular mass 194 detectable during rapid wing movement. (2) The strongest signals are detected when single males were mixed with other males or females. The

282 ferrulactone signal released from male-male or male-female is substantially greater than the sum 283 of the individual signals from the separated males/females. (3) Ferrulactone can be passively released during flying, but only in very small amounts. (4) The occurrence of a stronger signal when males and males or females are together strongly suggests that a visible signal may be needed to trigger the release of ferrulactone. (5) The rate of release of the chemical from males is very fast, beginning less than 1 second after the male $P$. rapae is placed with a female, reaching a maximum after about one-half minute. (6) The molar mass of the single chemical detected by cDART-MS from male $P$. rapae corresponds to ferrulactone $\left(\mathrm{C}_{12} \mathrm{H}_{18} \mathrm{O}_{2}\right)$ and was confirmed by electron ionization mass spectrometry. (7) Dead females of the same species or other live butterfly species do not effectively trigger the release of aphrodisiac pheromones by male $P$. rapae. These observations are consistent with the current models of butterfly mating behavior, which suggest the initial location of potential mates occurs visually followed by the release of male aphrodisiac pheromone(s).

Based on liquid extraction of the wings of $P$. rapae and $P$. brassicae and off-line GC-MS measurements, Yildizhan et al. (Yildizhan et al., 2009) observed and identified more than 120 compounds, of which Ferrulactone was one of the major $P$. rapae components. Hexahydrofarnesyl acetone $\left(\mathrm{C}_{18} \mathrm{H}_{36} \mathrm{O}\right.$, molar mass 268) and Phytol $\left(\mathrm{C}_{20} \mathrm{H}_{40} \mathrm{O}\right.$, molar mass 296) were also present in significant amounts. This study did not reveal any ion signal at $m / z 269$ or 297, corresponding to the protonated ions of the two compounds. A possible reason is that the compounds are not sufficiently volatile at room temperature. The EI ion source used in the GCMS approach can ionize more efficiently non-polar and weakly polar compounds than the DART ion source. The concentrations of the compounds can be significantly increased in liquid extraction, which could explain why more ion peaks were observed in the GC-MS experiments. Furthermore, the extractions were performed on the whole wings and therefore resulted in the detection of many non-volatile compounds at room temperature or volatile compounds that only 
312 In this study, we have for the first time performed in vivo monitoring of male butterfly 313 aphrodisiac pheromones released while flying in real-time. Our results indicate that the release 314 of the aphrodisiac pheromones by male P. rapae may be triggered by a visual cue. The visual 315 cue may be an ultraviolet signal from the female wing, as suggested by several studies (Obara 316 and Hidaka, 1968; Obara and Majerus, 2000; Silberglied, 1979; Silberglied and Taylor, 1973).

317 Using cDART-MS, it may be possible to clarify the role of specific triggers, and to localize the 318 areas from which the pheromones are released on a wing. Dead females of the same species do 319 not effectively trigger the release of aphrodisiac pheromones. It indicates that there are other 320 cues other than visual ones that play a role in triggering male pheromone release. Our 321 experiments also show that some passive release of ferrulactone may occur. However, our 322 observations do not support a generalization of the observation of Andersson et al. (Andersson et 323 al., 2007) for a closely related species (Pieris napi) that significant passive release of 324 ferrulactone from males occurs. Our experiments clearly indicate that although some passive 325 release may occur, a substantial increase in the release of the pheromones occurs when single 326 males are mixed with other males or females of the same species. Further work is definitely 327 required to help better understand the release of aphrodisiac pheromones and determine the 328 behavioral, chemical, or physical factors that are associated with their release.

330 Acknowledgements - We appreciate the use of the mass spectrometry facility at the University 331 of Maryland at College Park for the use of the instruments and the financial support by the 332 National Science Foundation (NSF) (Grant No. CHE-0946988). Several butterflies used in this 333 study were provided by Professor Nathan I. Morehouse of the University of Pittsburg, Pittsburg, 334 PA. Discussions with Professor Morehouse and graduate student Eden McQueen of the 335 University of Pittsburg are gratefully acknowledged regarding the male pheromone of Pieris 336 rapae, raising specimens, and the EI mass spectrum of ferrulactone. 
341 Fig. 1. Schematic diagram of the confined DART ion source used in in-vivo real time 342 monitoring of male aphrodisiac pheromone release of small white butterflies. One or two 343 butterflies were placed in $150 \mathrm{~mL}$ jars. The specimen jars and cDART were connected using a $3441 / 16^{\prime \prime}$ (ID) peek tube. The air was used as the carrier gas at a flow rate of $0.2 \mathrm{~L} / \mathrm{min}$.

Fig. 2. (a) Typical cDART mass spectra of the effluent from a male and female $P$. rapae in a 347 single jar (top) and only one male (bottom). The bottom one is amplified by 50 times for clearer comparison; (b) three-minute continuous monitoring of aphrodisiac pheromone release related to the flight activity of butterflies; (c) and (d) total ion chromatograms obtained in the positive 350 mode. In the figures, bkg: background, M: single male, F: single female, F-F (M-M, F-M, or M351 F): two females (or males) were placed in two separate jars connected only by air flow; FF (MM, 352 FM or MF): two butterflies (male or female) were placed in the same jar, $\mathrm{F}(\mathrm{d})$ : dead female 353 butterfly, O: other butterfly species, as shown dotted lines. The ion intensities in the figures 354 correspond to the relative intensities, and the maximum ion counts were set as 100 .

Fig. 3. Structure of ferrulactone $\left(\mathrm{C}_{12} \mathrm{H}_{18} \mathrm{O}_{2}\right)$ and in-source CID mass spectra of the pheromones 357 released by small white butterflies obtained at orifice 1 voltage of $65 \mathrm{~V}$; and (b) SPME-GC-EI mass spectrum. The above results identified the $m / z, 195$ ion as protonated ferrulactone. 


\section{References}

Andersson, J., A.K. Borg-Karlson, N. Vongvanich, and C. Wiklund. 2007. Male sex pheromone release and female mate choice in a butterfly. J. Exp. Biol. 210:964-970.

Borges, D.L.G., R.E. Sturgeon, B. Welz, A.J. Curtius, and Z. Mester. 2009. Ambient Mass Spectrometric Detection of Organometallic Compounds Using Direct Analysis in Real Time. Anal. Chem. 81:9834-9839.

Carlsson, M.A., A. Schapers, D.R. Nassel, and N. Janz. 2013. Organization of the Olfactory System of Nymphalidae Butterflies. Chem. Senses. 38:355-367.

Chernetsova, E.S., G.E. Morlock, and I.A. Revelsky. 2011. DART mass spectrometry and its applications in chemical analysis. Russ. Chem. Rev.+. 80:235-255.

Cody, R.B. 2009. Observation of Molecular lons and Analysis of Nonpolar Compounds with the Direct Analysis in Real Time lon Source. Anal. Chem. 81:1101-1107.

Cody, R.B., J.A. Laramee, and H.D. Durst. 2005. Versatile new ion source for the analysis of materials in open air under ambient conditions. Anal. Chem. 77:2297-2302.

Costanzo, K., and A. Monteiro. 2007. The use of chemical and visual cues in female choice in the butterfly Bicyclus anynana. P. Roy. Soc. B-Biol. Sci. 274:845-851.

Goubault, M., T.P. Batchelor, R.S.T. Linforth, A.J. Taylor, and I.C.W. Hardy. 2006. Volatile emission by contest losers revealed by real-time chemical analysis. P. Roy. Soc. B-Biol. Sci. 273:2853-2859.

Haefliger, O.P., and N. Jeckelmann. 2007. Direct mass spectrometric analysis of flavors and fragrances in real applications using DART. Rapid Commun. Mass Sp. 21:1361-1366.

Hayashi, N., H. Kawaguchi, A. Nishi, and H. Komae. 1987. Gamma-Decalactone, an Odoriferous Compound from the Male Butterfly, Lethe-Marginalis Motschulsky. Z. Naturforsch. C. 42:10011002.

Hedenstrom, E., E.A. Wallin, J. Andersson, J. Bang, H.L. Wang, C. Lofstedt, O. Brattstrom, and P. Baquet. 2015. Stereoisomeric Analysis of 6,10,14-Trimethylpentadecan-2-ol and the Corresponding Ketone in Wing Extracts from African Bicyclus Butterfly Species. J. Chem. Ecol. 41:44-51.

Kan, E., and T. Hidaka. 1997. Role of male scent in the mating behavior of Pieris melete Menetries (Lepidoptera : Pieridae). J .Ethol. 15:87-93.

Karlson, P., and A. Betenandt. 1959. Pheromones (Ectohormones) in Insects. Annu. Rev. Entomol. 4:3958.

Karlson, P., and Schneide.D. 1973. Sexual Pheromones of Lepidoptera as Model Systems for Chemical Communication. Naturwissenschaften. 60:113-121.

Kim, H.J., E.H. Jee, K.S. Ahn, H.S. Choi, and Y.P. Jang. 2010. Identification of Marker Compounds in Herbal Drugs on TLC with DART-MS. Arch. Pharm. Res. 33:1355-1359.

Lessman, C.A., W.S. Herman, D.A. Schooley, L.W. Tsai, B.J. Bergot, and F.C. Baker. 1989. Detection of Juvenile Hormone-I, Hormone-li and Hormone-lii in Adult Monarch Butterflies (DanausPlexippus). Insect Biochem. 19:431-433.

$\mathrm{Li}, \mathrm{Y} .2012$. Confined direct analysis in real time ion source and its applications in analysis of volatile organic compounds of Citrus limon (lemon) and Allium cepa (onion). Rapid Commun. Mass Sp. 26:1194-1202.

$\mathrm{Li}, \mathrm{Y} .2013$. Applications of a confined DART (direct analysis in real time) ion source for online in vivo analysis of human breath. Anal. Methods 5:6933-6940.

Maleknia, S.D., T.M. Vail, R.B. Cody, D.O. Sparkman, T.L. Bell, and M.A. Adams. 2009. Temperaturedependent release of volatile organic compounds of eucalypts by direct analysis in real time (DART) mass spectrometry. Rapid Commun. Mass Sp. 23:2241-2246.

Meinwald, J., Y.C. Meinwald, J.W. Wheeler, T. Eisner, and L.P. Brower. 1966. Major Components in Exocrine Secretion of a Male Butterfly (Lycorea). Science 151:583-585. 
Nieberding, C.M., H. de Vos, M.V. Schneider, J.M. Lassance, N. Estramil, J. Andersson, J. Bang, E. Hedenstrom, C. Lofstedt, and P.M. Brakefield. 2008. The male sex pheromone of the butterfly Bicyclus anynana: towards an evolutionary analysis. PloS one 3:e2751.

Nishida, R., S. Schulz, C.S. Kim, H. Fukami, Y. Kuwahara, K. Honda, and N. Hayashi. 1996. Male sex pheromone of a giant danaine butterfly, Idea leuconoe. J. Chem. Ecol. 22:949-972.

Obara, Y., and T. Hidaka. 1968. Recognition of Female by Male on Basis of Ultra-Violet Reflection in White Cabbage Butterfly Pieris Rapae Crucivora Boisduval. P. Jpn. Acad. 44:829-832.

Obara, Y., H. Koshitaka, and K. Arikawa. 2008. Better mate in the shade: enhancement of male mating behaviour in the cabbage butterfly, Pieris rapae crucivora, in a UV-rich environment. J. Exp. Biol. 211:3698-3702.

Obara, Y., and M.E.N. Majerus. 2000. Initial mate recognition in the British cabbage butterfly, Pieris rapae. Zool. Sci. 17:725-730.

Omura, H., K. Honda, and N. Hayashi. 2001. Identification of odoriferous compounds from adults of a swallowtail butterfly, Papilio machaon (Lepidoptera : Papilionidae). Z. Naturforsch. C. 56:11261134.

Papke, R.S., D.J. Kemp, and R.L. Rutowski. 2007. Multimodal signalling: structural ultraviolet reflectance predicts male mating success better than pheromones in the butterfly Colias eurytheme $\mathrm{L}$. (Pieridae). Animal Behaviour 73:47-54.

Robertson, K.A., and A. Monteiro. 2005. Female Bicyclus anynana butterflies choose males on the basis of their dorsal UV-reflective eyespot pupils. P. Roy. Soc. B-Biol. Sci. 272:1541-1546.

Rutowski, R.L. 1977a. Chemical Communication in Courtship of Small Sulfur Butterfly Eurema-Lisa (Lepidoptera, Pieridae). J. Comp. Physiol. 115:75-85.

Rutowski, R.L. 1977b. Use of Visual Cues in Sexual and Species Discrimination by Males of Small Sulfur Butterfly Eurema-Lisa (Lepidoptera, Pieridae). J .Comp. Physiol. 115:61-74.

Rutowski, R.L. 1980. Male Scent-Producing Structures in Colias Butterflies - Function, Localization, and Adaptive Features. J. Chem. Ecol. 6:13-26.

Rutowski, R.L. 1991. The Evolution of Male Mate-Locating Behavior in Butterflies. Am. Nat. 138:11211139.

Schulz, S., M. Boppre, and R.I. Vanewright. 1993. Specific Mixtures of Secretions from Male Scent Organs of African Milkweed Butterflies (Danainae). Philos. T. Roy. Soc. B. 342:161-181.

Schulz, S., and R. Nishida. 1996. The pheromone system of the male danaine butterfly, Idea leuconoe. Bioorgan. Med. Chem. 4:341-349.

Silberglied, R.E. 1979. Communication in the Ultraviolet. Annu. Rev. Ecol. Syst. 10:373-398.

Silberglied, R.E., and O.R. Taylor. 1973. Ultraviolet Differences between Sulfur Butterflies, ColiasEurytheme and C Philodice, and a Possible Isolating Mechanism. Nature 241:406-408.

Tillman, J.A., S.J. Seybold, R.A. Jurenka, and G.J. Blomquist. 1999. Insect pheromones--an overview of biosynthesis and endocrine regulation. Insect biochemistry and molecular biology. 29:481-514.

Tinbergen, N., B.J.D. Meeuse, L.K. Boerema, and W.W. Varossieau. 1942. Z. Tierpsychol. 5:182.

Witzgall, P., P. Kirsch, and A. Cork. 2010. Sex pheromones and their impact on pest management. J. Chem. Ecol. 36:80-100.

Yew, J.Y., R.B. Cody, and E.A. Kravitz. 2008. Cuticular hydrocarbon analysis of an awake behaving fly using direct analysis in real-time time-of-flight mass spectrometry. P. Natl. Acad. Sci. USA 105:7135-7140.

Yildizhan, S., J. van Loon, A. Sramkova, M. Ayasse, C. Arsene, C. ten Broeke, and S. Schulz. 2009. Aphrodisiac Pheromones from the Wings of the Small Cabbage White and Large Cabbage White Butterflies, Pieris rapae and Pieris brassicae. Chembiochem. 10:1666-1677. 
$456 \quad$ Fig. 1

457

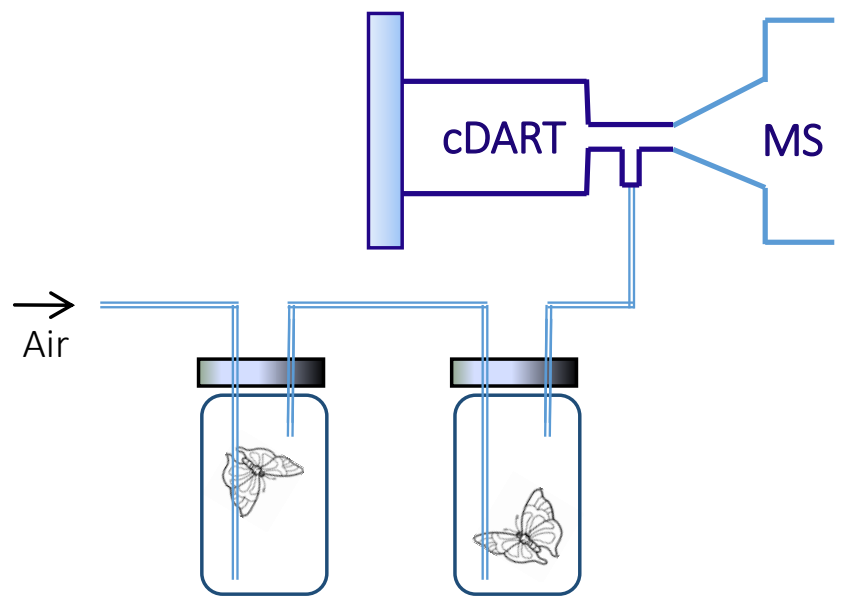

459

460 
Fig. 2(a)

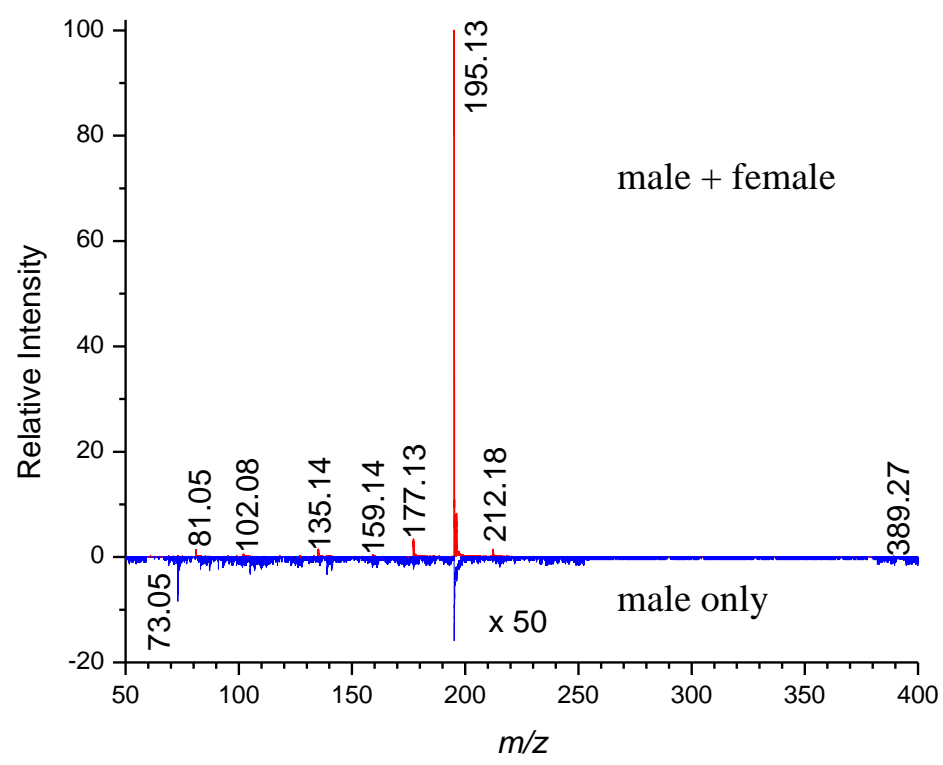

462

463

Fig. 2(b)

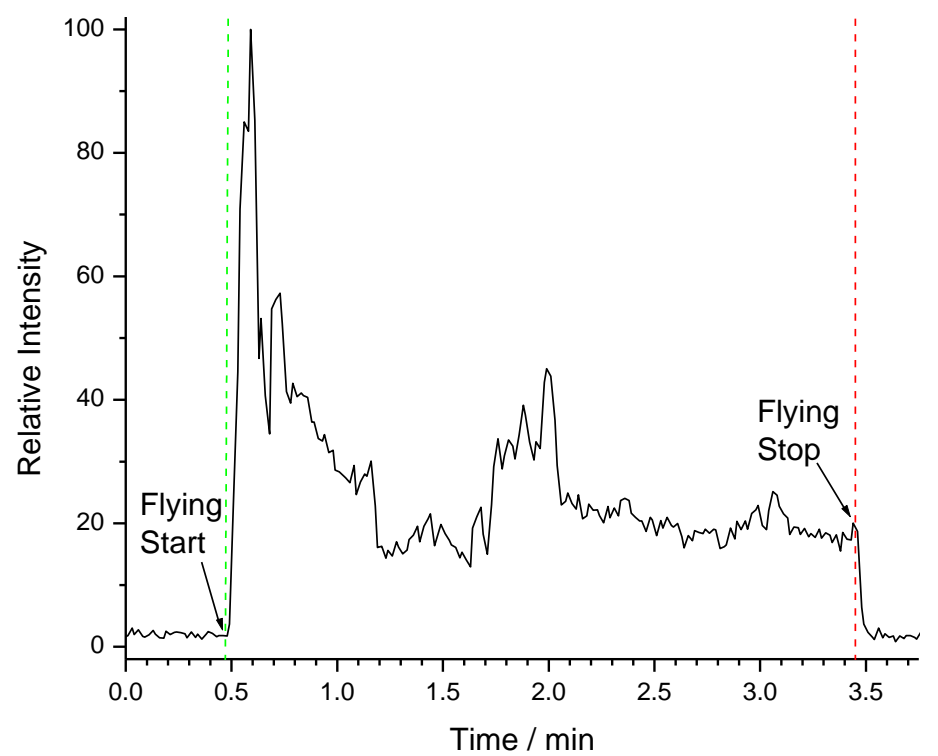

464

465 
Fig. 2(c)

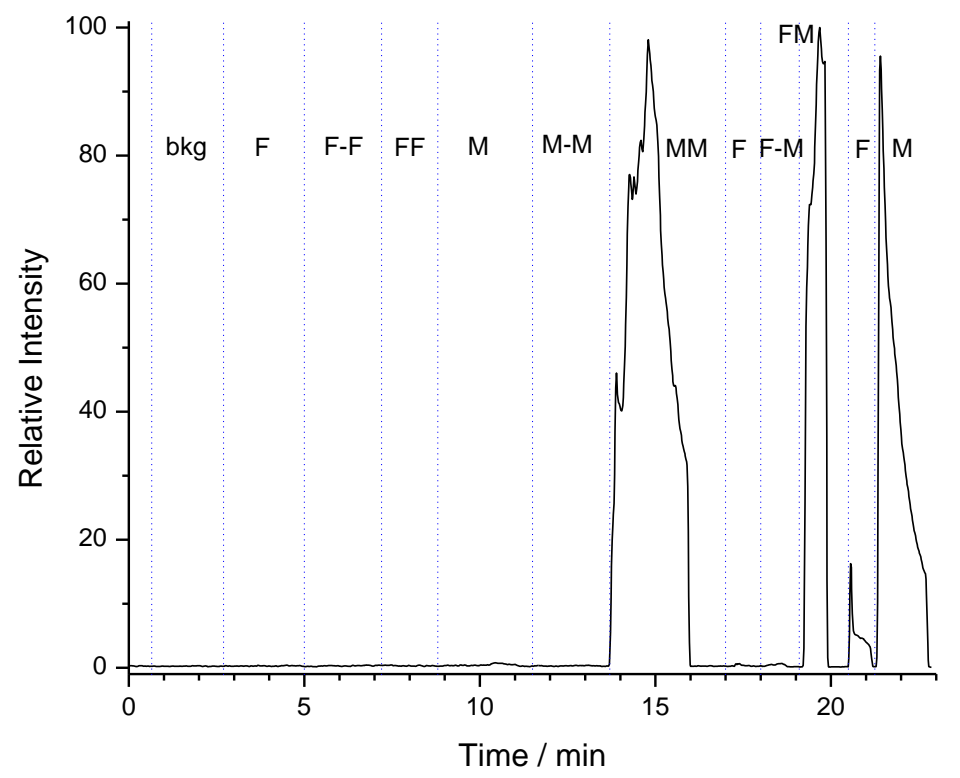

468

469

Fig. 2(d)

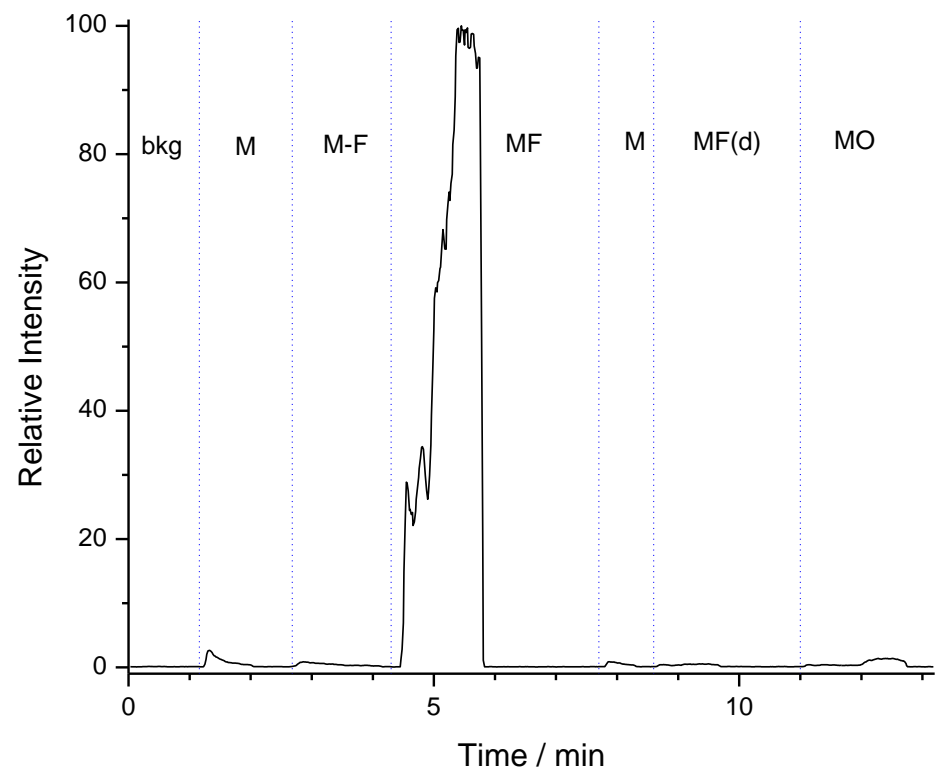

470

471 
472 Fig. 3(a)

473

474

475

476

477

478

479

480

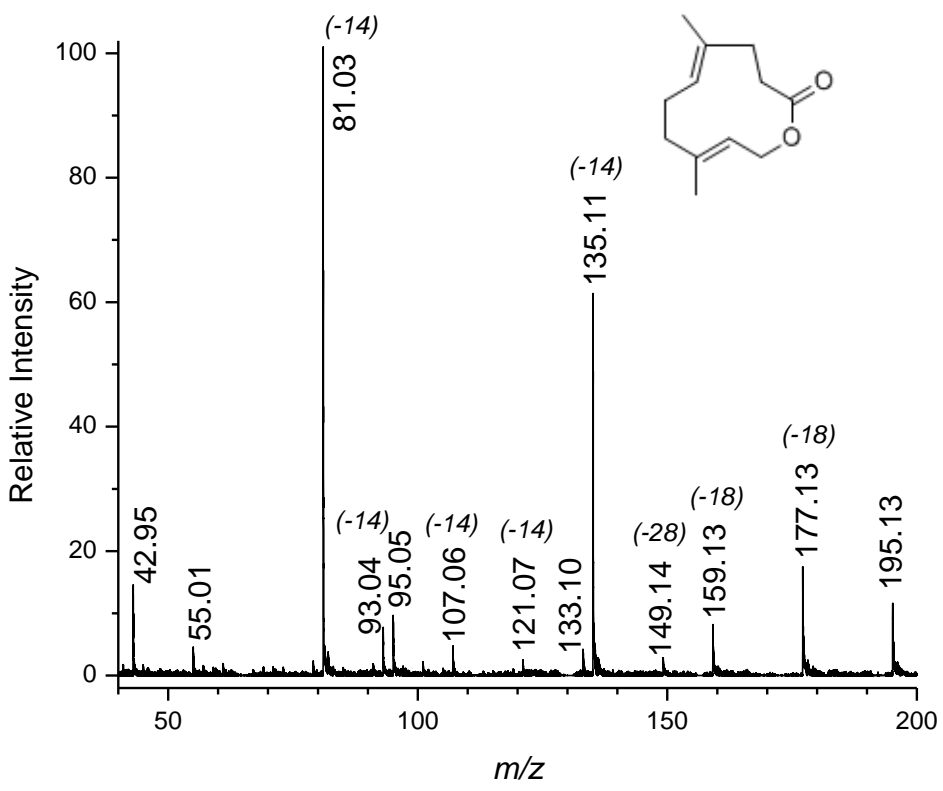

481

482 Fig. 3(b)

483

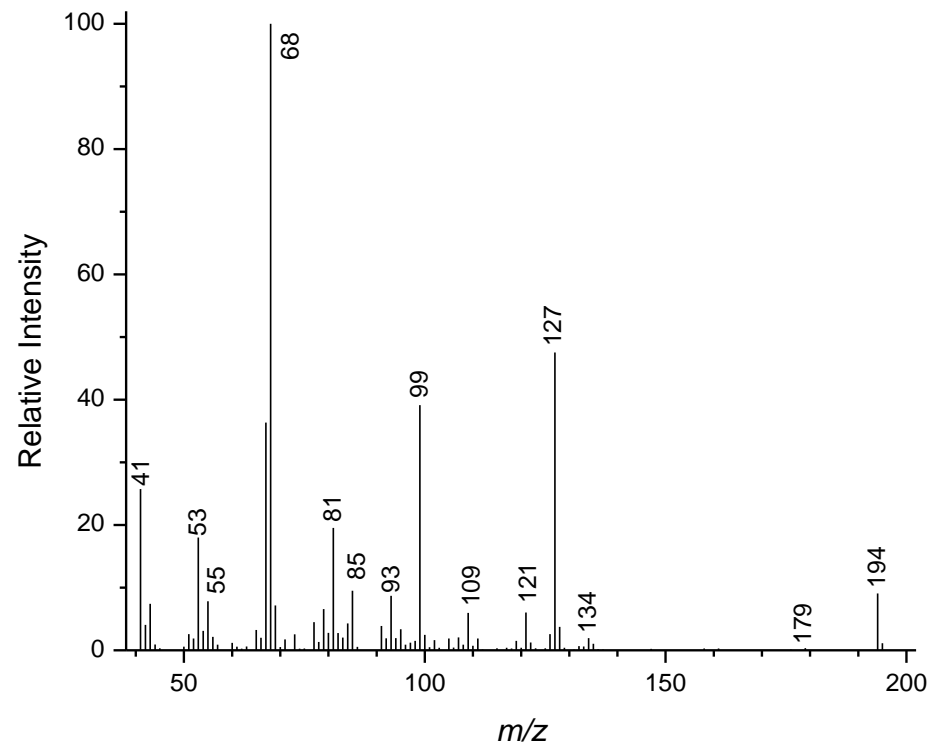

